Oбработка металлов
(технология • оборудование • инструменты)

Об участии водорода в формировании свойств заэвтектических сплавов Al-Si Владимир Афанасьев ${ }^{a}$, Марина Попова ${ }^{b, ~}$, Марина Малюх ${ }^{c}$, Светлана Долгова ${ }^{d}$

Сибирский государственный индустриальный университет, ул. Кирова, 42, г. Новокузнецк, 654007, Россия

${ }^{a}$ (D) https://orcid.org/0000-0003-0178-5471, @ in_afanaseva@mail.ru, ${ }^{b}$ (D) https://orcid.org/0000-0001-8010-9134, @ m.popova@rdtc.ru,

${ }^{c}$ (D) https://orcid.org/0000-0003-2299-9292, @ starostina_ma1976@mail.ru, ${ }^{d}$ (D) https://orcid.org/0000-0002-8044-196X, 9 sv_dolgov@mail.ru

ИНФОРМАЦИЯ О СТАТЬЕ

УДК 669.715'788.017

\section{История статьи:}

Поступила: 02 февраля 2018

Рецензирование: 26 февраля 2018

Принята к печати: 17 марта 2018

Доступно онлайн: 15 июня 2018

\section{Ключевые слова:}

Сплавы Al-Si

Водород

Кристаллы первичного кремния

Кристаллизация

Деформация

Температурный коэффициент

линейного расширения

\begin{abstract}
АННОТАЦИЯ
Введение. Алюминиевые сплавы специального назначения характеризуются определенным сочетанием механических, физических и химических свойств, что обусловлено эксплуатацией в строго определенных условиях. При разработке новых материалов с улучшенными технологическими свойствами большое внимание уделяется сплавам системы Al-Si заэвтектической концентрации. Известно, что комбинированные модифицирующие вещества, состоящие из двух и более компонентов, по эффективности превосходят каждый компонент в отдельности. Существует много способов модифицирования таких сплавов с целью измельчения первичных кристаллов кремния и эвтектики. Большинство известных технологий не нашли широкого применения на практике, поэтому разработка способа модифицирования расплава водородосодержащими соединениями остается актуальной темой. Цель работы: создание технологичного способа обработки расплава, предусматривающего увеличение содержания водорода, для модифицирования структуры в литом состоянии и получения деформированных сплавов $\mathrm{Al}-15 \ldots 30$ \% Si с улучшенными физико-механическими свойствами. В работе исследованы параметры микроструктуры в литом состоянии и после горячей пластической деформации, а также механические характеристики модифицированных сплавов. Проведено изучение микроструктуры полученных сплавов. Методами исследования являются дилатометрические испытания, механические испытания на статическое растяжение, а также металлографический анализ исследуемых сплавов. Результаты и обсуждение. Разработан новый способ модифицирования, позволяющий резко уменьшить размер первичных кристаллов кремнистой фазы, вследствие чего значительно повышаются механические свойства высококремнистых сплавов и их деформируемость. Применение предложенного способа позволяет получить структуру эвтектического типа в заэвтектических сплавах Al-Si. Благодаря получению модифицированной структуры, характеризующейся повышенной степенью дисперсности составляющих, резкому уменьшению размеров первичных кристаллов хрупкой кремнистой фазы и благоприятному изменению их формы, стала возможной пластическая деформация исследуемых сплавов. Установлено, что горячая деформация оказывает положительное влияние на механические свойства сплавов $\mathrm{Al}-\mathrm{Si}$, особенно на их пластичность. Показано, что комплекс физико-механических свойств деформированных полуфабрикатов превышает даже свойства спеченных алюминиевых сплавов.
\end{abstract}

Для цитирования: Об участии водорода в формировании свойств заэвтектических сплавов Al-Si / В.К. Афанасьев, М.В. Попова, М.А. Малюх, С.В. Долгова // Обработка металлов (технология, оборудование, инструменты). - 2018. - Т. 20, № 2. - С. 63-74. - doi: 10.17212/1994-6309-2018-20.2-63-74.

\section{Введение}

Развитие современной аэрокосмической промышленности требует создания новых легких металлических материалов, которые обеспечат большую весовую отдачу деталей и стабильность

\footnotetext{
*Адрес для переписки

Попова Марина Владимировна, д.т.н, профессор

Сибирский государственный индустриальный университет

ул. Кирова, 42,

654007, г. Новокузнецк, Россия

Тел.: 8 (384) 346-32-91, e-mail: m.popova@rdtc.ru
}

размеров [1]. При разработке таких материалов особое внимание уделяется заэвтектическим сплавам системы Al-Si. Основным преимуществом, определяющим перспективность их использования, является благоприятное сочетание малого удельного веса, низкого температурного коэффициента линейного расширения (ТКЛР) и высокой износостойкости. Основной недостаток заэвтектических сплавов $\mathrm{Al}-\mathrm{Si}$ - низкие механические свойства, которые контролируются количеством, размерами и характером распределения 
кристаллов первичного кремния (КПК) и наличием грубой эвтектики.

Важнейшим методом повышения свойств сплавов Al-Si является легирование. Известно, что помимо основных легирующих элементов на структуру и свойства сплавов оказывают влияние примеси, попадающие в расплав на различных стадиях их получения. Имеется много научных публикаций, подтверждающих активное участие водорода в формировании структуры и технологических свойств алюминиевых сплавов, получаемых различными способами [2-6]. Водород взаимодействует с алюминиевыми сплавами на всех этапах их выплавки [7]. Авторами [8] отмечается, что алюминий насыщается водородом в процессе электролиза криолитоглиноземного расплава, осаждаясь вместе с металлом на катоде. Содержание водорода зависит от чистоты и вида шихты, а также условий ее хранения. Степень наводороживания расплава зависит от влажности атмосферы печи, от площади зеркала расплава, а также от температуры и времени выплавки сплава. Один из источников попадания водорода в расплав - печная атмосфера. Кроме того, водород попадает в расплав из атмосферы печи за счет адсорбционных процессов, которые можно регулировать изменением площади зеркала расплава путем оптимального выбора плавильной печи. Большое значение имеет содержание воды в солях, применяемых для модифицирования, и влажность форм, в которые осуществляется заливка [9].

Исследования многих авторов показывают, что водород оказывает значительное влияние на развитие пористости и за счет этого может снижать механические свойства $[10,11]$. Однако необходимо понимать, что механические свойства снижает только водород, перешедший в молекулярную форму, а атомарный диффузионно-подвижный водород не вызывает образования пористости. Есть сведения о возможности упрочнения сплавов за счет увеличения содержания в них водорода [12, 13].

В публикациях неоднократно отмечается, что важное значение имеют условия кристаллизации сплавов Al-Si. B работах [14-17] убедительно показано, что высокие скорости кристаллизации способствуют улучшению микроструктуры и благоприятно влияют на физико-механические свойства исследуемых сплавов. Кроме того, алюминиевые сплавы, полученные с высокими скоростями кристаллизации, могут быть использованы в качестве сплавов - накопителей водорода [18].

Обзор публикаций по проблеме исследования позволяет утверждать, что водород может оказывать значительное влияние на механические и физические свойства сплавов системы $\mathrm{Al}-\mathrm{Si}$, однако его использование для повышения свойств сплавов, содержащих более $15 \% \mathrm{Si}$, изучено недостаточно. В частности, имеется мало сведений о влиянии пластической деформации на свойства высококремнистых силуминов, в основном проводятся исследования режимов деформации и свойств деформированных сплавов околоэвтектического состава, дополнительно легированных медью, магнием, титаном, цирконием [19-21].

Для обеспечения необходимого комплекса свойств нами ранее были разработаны многочисленные способы модифицирования сплавов системы Al-Si водородосодержащими веществами $[22,23]$, однако не было показано, как эти способы влияют на способность к пластической деформации сплавов алюминия с $15 \ldots 30$ \% кремния.

Цель настоящего исследования - создание технологичного способа обработки расплава, предусматривающего увеличение содержания водорода, для модифицирования структуры в литом состоянии и получения деформированных сплавов $\mathrm{Al}-15 \ldots 30 \% \mathrm{Si}$ с улучшенными свойствами.

\section{Методика исследований}

Для выплавки сплавов использовали технически чистые металлы и лигатуры. Для приготовления сплавов применяли закрытые лабораторные печи типа СШОЛ и печи шахтного типа с нагревателями из карбида кремния.

В зависимости от назначения вес плавки составлял 0,5 ..5 кг. Рабочие температуры от 600 до $1400{ }^{\circ} \mathrm{C}$. Для устранения действия побочных факторов при температурах расплава выше $750 \ldots 800{ }^{\circ} \mathrm{C}$ использовали алундовые тигли.

Для изменения структуры и свойств отливок использовали различные виды обработки расплава, в том числе проводили наводороживание 
расплава путем введения гидрида лития и выстаивания в атмосфере водяного пара.

Модифицирование фосфористой медью в количестве $0,1 \ldots 0,2$ \% от массы расплава осуществляли при $1000^{\circ} \mathrm{C}$. Комплексное модифицирование расплава фосфористой медью и гидридом лития в количестве 0,1 \% от массы расплава проводили при температуре $850 \ldots 900{ }^{\circ} \mathrm{C}$. Сначала вводили фосфористую медь, затем расплав обрабатывали гидридом лития. Однако введение его в расплав сопровождалось пироэффектами, а также выбросами металла, вероятность и интенсивность которых возрастают при повышении температуры расплава.

Наиболее технологично наводороживание расплава за счет выстаивания его в атмосфере водяного пара, которое осуществляли следующим образом. В закрытую печь через фарфоровую трубку на поверхность расплава каплями подавалась вода. При попадании на поверхность жидкого металла вода превращалась в пар, водяной пар разлагался по реакции $\mathrm{H}_{2} \mathrm{O} \rightarrow 2 \mathrm{H}+\mathrm{O}$, что приводило к насыщению расплава водоро-

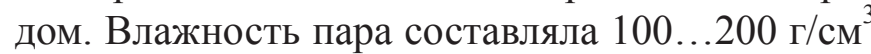
при нормальном давлении, поэтому наводороживание расплава определялось его температурой и временем обработки. Использование предложенной методики при обычных температурах плавки (до $1000{ }^{\circ} \mathrm{C}$ ) позволяет изменять содержание водорода в отливках, залитых в кокиль от 0,1 до $10 \mathrm{~cm}^{3} / 100$ г металла. Для исследований был выбран режим выстаивания в атмосфере водяного пара при $920{ }^{\circ} \mathrm{C}$ в течение $15 \ldots 45$ мин.

После обработки расплав выдерживали в течение 10..15 мин и заливали в холодный алюминиевый кокиль (скорость охлаждения $\left.\sim 10 \ldots 30{ }^{\circ} \mathrm{C} / \mathrm{c}\right)$. Контроль температуры расплава проводили термопарами: в интервале $600 \ldots 1100{ }^{\circ} \mathrm{C}$ хромель-алюмелевой, а в интервале $1100 \ldots 1400{ }^{\circ} \mathrm{C}$ вольфрам-рениевой.

Пластическую деформацию изучаемых сплавов осуществляли свободной ковкой и прокаткой. Прокатку проводили на лабораторном одноклетьевом двухвалковом реверсивном стане с диаметром валков 130 мм и скоростью прокатки 0,5 м/с. Привод движения осуществляли на нижний валок с передачей вращения на верхний валок шестеренной парой. Степень обжатия регулировали нажимным устройством. Мощность двигателя стана составляла 20 кВт. Образцы на- гревали до температуры $500 \ldots 550{ }^{\circ} \mathrm{C}$. Обжатие за проход, количество проходов и суммарное обжатие изменялось в зависимости от структуры и свойств сплавов. Исходная толщина заготовок составляла 15..30 мм, конечная 1..3 мм. Конечная степень деформации проката составляла: 94, 91 и $89 \%$ для сплавов алюминия с 15, 20 и $30 \%$ Si соответственно.

Ковку исполняли на пневматическом молоте с массой падающих частей 150 кг. Нагретые до указанных температур слитки протягивали со степенью вытяжки 4 и 16, что соответствовало деформации 75 и $94 \%$.

Термическая обработка сплавов, проводимая на разных этапах эксперимента, включала в себя смягчающий отжиг литых заготовок, нагрев под деформацию и промежуточный отжиг, а также отжиг деформированных образцов. Температура нагрева при отжиге и деформации сплавов была примерно одинаковой и составляла $500 \ldots 530{ }^{\circ} \mathrm{C}$. Нагрев образцов осуществляли в печах типа СНОЛ. Температуру контролировали с помощью термопары хромель-алюмель.

Микроструктуру сплавов изучали в литом состоянии и после пластической деформации. Для изучения литой структуры отрезали темплет от донной части слитков, на котором готовился шлиф. Структуру деформированных полуфабрикатов изучали на шлифах, вырезанных как вдоль, так и поперек направления деформации.

Изучение микроструктуры сплавов проводилось с помощью оптического микроскопа OLYMPUS GX-51.

Содержание атомарного водорода определяли на лабораторной установке В-1 методом вакуум-нагрева в соответствии с ГОСТ 21132.1-98. Алюминий и сплавы алюминиевые. Метод определения водорода в твердом металле вакуум-нагревом. Метод основан на экстракции водорода из анализируемого металла, нагретого ниже температуры плавления, в диапазоне $500 \ldots 600{ }^{\circ} \mathrm{C}$, в вакууме при остаточном давлении $(6,65 \ldots 9,31) 10^{-5}$ Па. Установка позволяет определять содержание водорода с точностью до $0,15 \mathrm{~cm}^{3} / 100$ г металла.

Испытания на статическое растяжение при обычной температуре проводили на разрывной машине УММ-5 по ГОСТ 1497-84. Для испытаний использовали образцы с рабочей частью в виде цилиндра или стержня с прямоугольным 
сечением (плоские образцы). Из деформированных заготовок образцы вырезали вдоль направления деформации. По каждому режиму проводили испытания на трех образцах. При этом суммарная погрешность определения предела прочности не превышала \pm 3 МПа, относительного удлинения $\pm 0,1 \%$.

Тепловое расширение сплавов изучали с помощью фоторегистрирующего дифференциального оптического дилатометра системы Шевенара в интервале температур $20 \ldots 450{ }^{\circ} \mathrm{C}$. ТКЛР рассчитывали методом касательных. Суммарная погрешность его определения составляла $\pm 0,16 \cdot 10^{-6} 1 /{ }^{\circ} \mathrm{C}$.

\section{Результаты и их обсуждение}

При исследовании влияния модифицирования на структуру и свойства сплавов, содержащих $15 \ldots 30 \% \mathrm{Si}$, было установлено, что при обработке расплава модификаторами, в состав которых входят фосфор- и водородсодержащие вещества, достигается увеличение содержания водорода в слитках и значительное измельчение кристаллов кремнистой фазы. Микроструктура сплавов $\mathrm{Al}-20 \% \mathrm{Si}$ до и после обработки расплава предложенными выше модификаторами приведена на рис. 1.

В микроструктуре сплава обычного приготовления присутствуют грубые кристаллы кремнистой фазы неправильной формы и тонкодисперсная эвтектика $(\alpha+\mathrm{Si})$. Из-за неравновесной кристаллизации в структуре имеются дендриты $\alpha$-твердого раствора, окаймляющие первичные кристаллы кремнистой фазы. В результате обработки расплава широко применяемым в промышленности модификатором $\mathrm{Cu}_{3} \mathrm{P}$ в сплаве $\mathrm{Al}-20 \% \mathrm{Si}$ размер кристаллов кремнистой фазы уменьшается до 50..60 мкм и они приобретают более округлую форму, однако про-

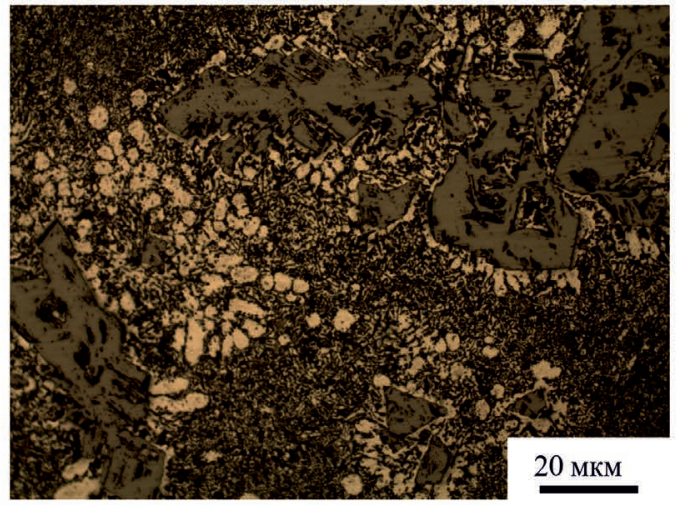

$a$

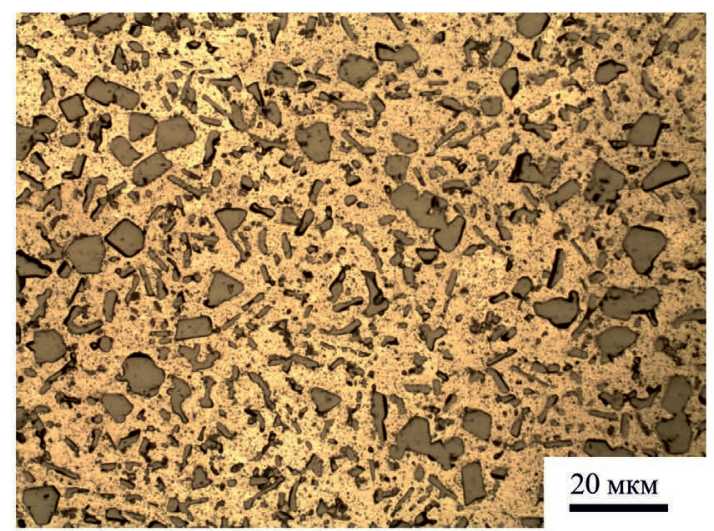

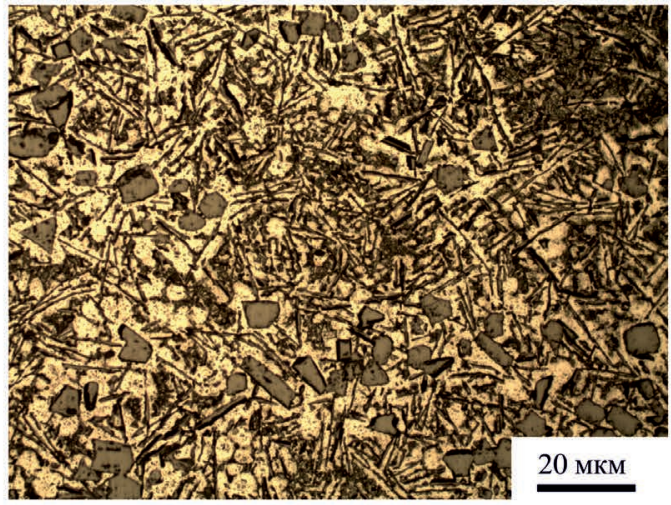

б

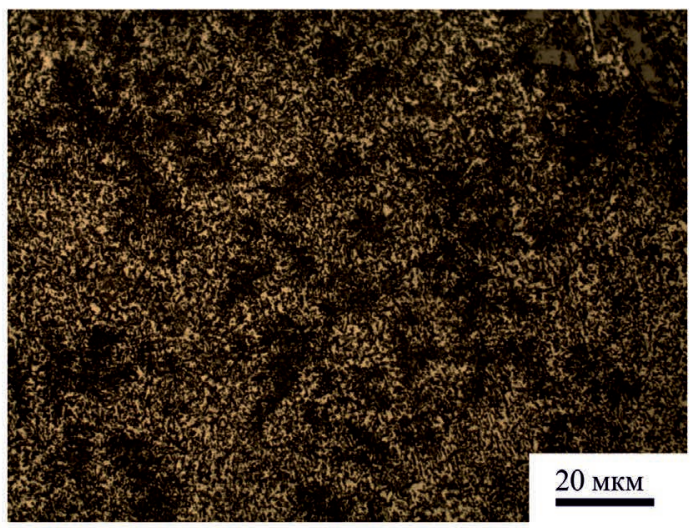

Puc. 1. Микроструктура сплава Al - 20 \% Si:

обычного приготовления $(a)$; модифицированного $\mathrm{Cu}_{3} \mathrm{P}\left(\right.$ б); модифицированного $\mathrm{Cu}_{3} \mathrm{P}+\mathrm{LiH}($ в); наводороженного (2)

Fig. 1. The microstructure of the $\mathrm{Al}-20 \% \mathrm{Si}$ alloy: traditionally preparated $(a)$; modified by $\mathrm{Cu}_{3} \mathrm{P}(\sigma)$; modified by $\mathrm{Cu}_{3} \mathrm{P}+\mathrm{LiH}(6)$; the hydrogen-saturated (2) 
исходит огрубление эвтектики. При комплексном модифицировании, которое заключалось в обработке смесью $\mathrm{Cu}_{3} \mathrm{P}+\mathrm{LiH}$, формируются мелкодисперсные КПК, размер которых не превышает 20 мкм. По сравнению с широко применяемым в промышленности способом обработки расплава $\mathrm{Cu}_{3} \mathrm{P}$ применение комплексного модифицирования смесью $\mathrm{Cu}_{3} \mathrm{P}+\mathrm{LiH}$ весьма эффективно: содержание водорода в сплавах увеличивается примерно в два раза, при этом средний размер первичных кристаллов кремния уменьшается примерно в два раза, предельная степень пластической деформации увеличивается в $1,1 \ldots 1,4$ раза.

На рис. 1, г представлена микроструктура сплава $\mathrm{Al}$ - $20 \% \mathrm{Si}$, наводороженного путем выстаивания в атмосфере водяного пара при $920{ }^{\circ} \mathrm{C}$ в течение 45 мин. Обработка расплава этим способом позволяет увеличить количество определяемого атомарного водорода до $2,3 \mathrm{~cm}^{3} / 100$ г металла и получить эвтектическую тонкодисперсную структуру, характерную для сплавов $\mathrm{Al}-10 \ldots 13 \% \mathrm{Si}$.

Механические характеристики сплава $\mathrm{Al}-$ $20 \% \mathrm{Si}$, выплавленного без модифицирования, модифицированного $\mathrm{Cu}_{3} \mathrm{P}$, смесью $\mathrm{Cu}_{3} \mathrm{P}+\mathrm{LiH}$ и наводороженного, представлены в табл. 1. Видно, что предел прочности сплавов, подвергнутых обработке путем выстаивания в атмосфере водяного пара, увеличивается в 1,4...1,5 раза по сравнению со сплавом обычного приготовления, а относительное удлинение возрастает в $2 . .2,5$ раза.
Столь существенное увеличение механических свойств обусловлено структурными изменениями.

Благодаря получению модифицированной структуры для сплавов $\mathrm{Al}-15 \ldots 30 \% \mathrm{Si}$, характеризующейся резким уменьшением размеров КПК и благоприятным изменением строения эвтектики от пластинчатой к глобулярной, стала возможной пластическая деформация исследуемых сплавов.

После проведения пластической деформации, которую осуществляли путем свободной ковки и прокатки, проводили металлографические исследования и механические испытания. Механические характеристики проката определяли также после проведения отжига $\left(500{ }^{\circ} \mathrm{C}\right.$ в течение 10 ч), который необходим для снятия внутренних напряжений и повышения пластичности.

Микроструктура слитков после деформации показана на рис. 2, $a$ механические характеристики - в табл. 2. Можно отметить, что горячая деформация оказывает положительное влияние на механические свойства, особенно на пластичность силуминов. Причиной такого повышения свойств является улучшение структуры при деформации, прежде всего измельчение и сфероидизация КПК и эвтектических частиц кремнистой фазы.

Таким образом, применение разработанного способа модифицирования позволяет повысить деформируемость и механические характеристики заэвтектических сплавов системы Al-Si после горячей пластической деформации. При этом

Т а блица 1 Table 1

Сравнительные механические свойства сплава $\mathrm{Al}-20$ \% $\mathrm{Si}$

Comparative mechanical properties of the alloy $\mathrm{Al}-20 \% \mathrm{Si}$

\begin{tabular}{|c|c|c|c|}
\hline \multirow{2}{*}{$\begin{array}{l}\text { Способ приготовления / } \\
\text { Method of preparation }\end{array}$} & \multicolumn{2}{|c|}{$\begin{array}{c}\text { Механические характеристики / } \\
\text { Mechanical properties }\end{array}$} & \multirow{2}{*}{$\begin{array}{c}\text { Содержание } \\
\text { водорода, } \\
\mathrm{cm}^{3} / 100 \text { г Ме }\end{array}$} \\
\hline & $\begin{array}{c}\text { Предел прочности, } \\
\sigma_{\mathrm{B}}, \text { МПа }\end{array}$ & $\begin{array}{l}\text { Относительное } \\
\text { удлинение, } \delta, \%\end{array}$ & \\
\hline Без обработки расплава & 97 & 0,8 & 0,3 \\
\hline Модифицирование расплава 0,1 \% $\mathrm{Cu}_{3} \mathrm{P}$ & 134 & 1,6 & 0,7 \\
\hline $\begin{array}{l}\text { Модифицирование расплава } 0,1 \text { \% смеси } \\
\mathrm{Cu}_{3} \mathrm{P}+\mathrm{LiH}\end{array}$ & 147 & 1,5 & 1,5 \\
\hline $\begin{array}{l}\text { Выстаивание расплава в атмосфере } \\
\text { водяного пара }\end{array}$ & 145 & 2,0 & 2,3 \\
\hline
\end{tabular}




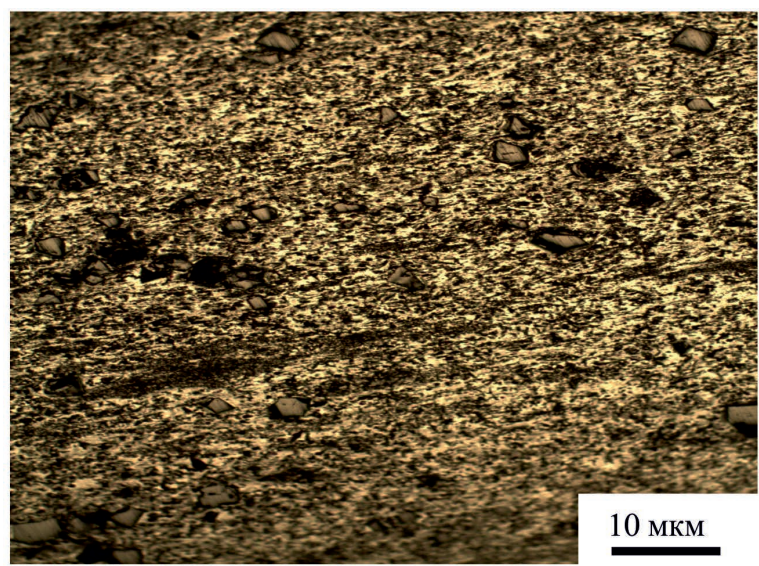

$a$

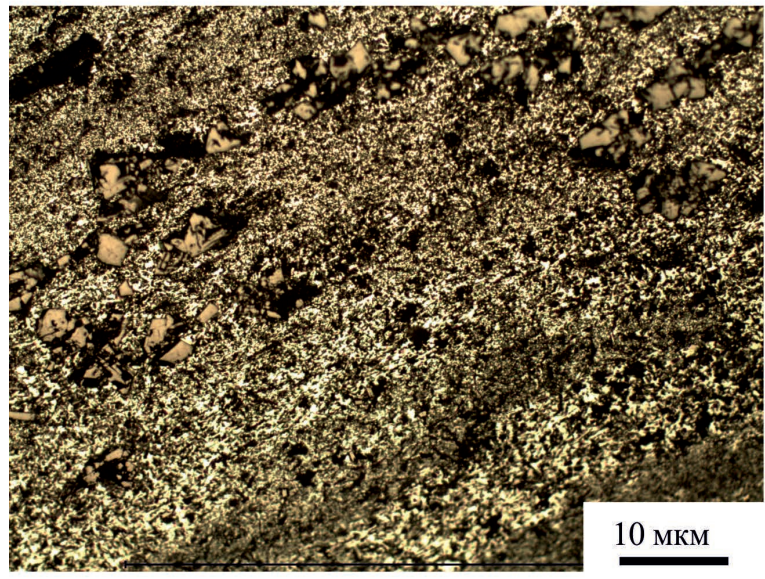

B

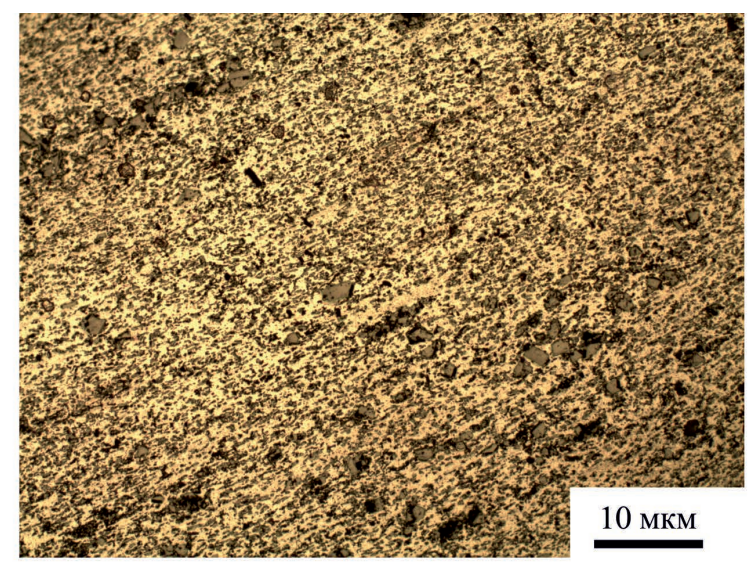

$\sigma$

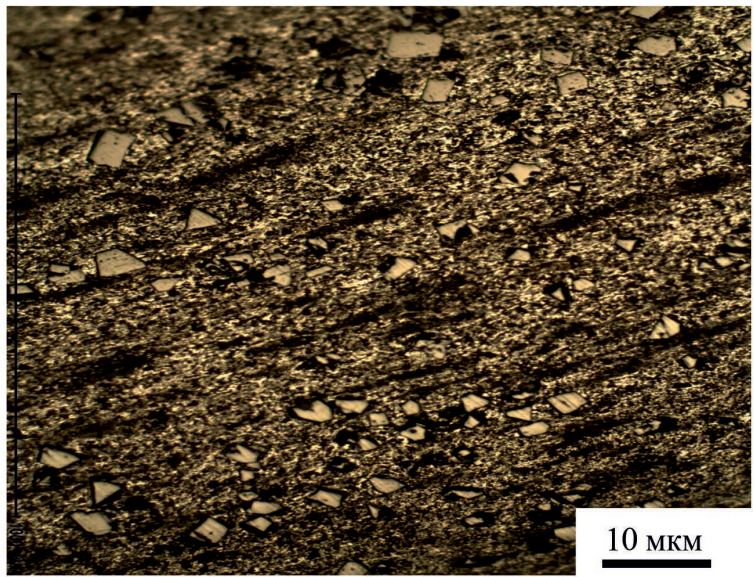

Puс. 2. Микроструктура деформированных заэвтектических сплавов Al-Si:

сплава $\mathrm{Al}$ - 15 \% Si (a); модифицированного сплава $\mathrm{Al}$ - 15 \% Si (б); сплава $\mathrm{Al}$ - 20 \% Si (в); модифицированного сплава $\mathrm{Al}-20 \% \mathrm{Si}(2)$

Fig. 2. The deformed microstructure of hypereutectic Al-Si alloys:

$\mathrm{Al}-15 \% \mathrm{Si}$ alloy (a); the modified $\mathrm{Al}-15 \% \mathrm{Si}$ alloy (6); $\mathrm{Al}-20 \% \mathrm{Si}$ alloy (b); the modified $\mathrm{Al}-20 \% \mathrm{Si}$ alloy (2)

Та блица 2

Table 2

Механические характеристики сплавов в зависимости от технологии обработки /

The mechanical properties of the alloys depending on the processing technologie

\begin{tabular}{|l|c|c|c|c|c|c|}
\hline \multirow{2}{*}{$\begin{array}{c}\text { Технология обработки / } \\
\text { Processing technology }\end{array}$} & \multicolumn{5}{|c|}{$\begin{array}{c}\text { Механические характеристики сплавов / } \\
\text { The mechanical characteristics of the alloys }\end{array}$} \\
\cline { 2 - 7 } & \multicolumn{2}{|c|}{$\mathrm{Al}-15 \% \mathrm{Si}$} & \multicolumn{2}{c|}{$\mathrm{Al}-20 \% \mathrm{Si}$} & \multicolumn{2}{c|}{$\mathrm{Al}-30 \% \mathrm{Si}$} \\
\cline { 2 - 7 } & $\sigma_{\mathrm{B}}, \mathrm{M \Pi a}$ & $\delta, \%$ & $\sigma_{\mathrm{B}}, \mathrm{M \Pi a}$ & $\delta, \%$ & $\sigma_{\mathrm{B}}, \mathrm{M \Pi а}$ & $\delta, \%$ \\
\hline Литой & 166 & 2,2 & 145 & 2,0 & 120 & 0,5 \\
\hline Прокат & 186 & 0,7 & 198 & 0,2 & 130 & 0,1 \\
\hline Прокат и отжиг & 216 & 8,2 & 217 & 5,6 & 161 & 2,3 \\
\hline Ковка & 256 & 6,6 & 238 & 5,2 & 215 & 3,0 \\
\hline
\end{tabular}


механические свойства деформированных полуфабрикатов превышают даже свойства спеченных алюминиевых сплавов [24]. Так, прокат и поковки, полученные из силуминов с содержанием кремния 15, 20 и $30 \%$, имеют предел прочности в 1,5 ..1,8 раза выше, чем сплавы в литом состоянии. Относительное удлинение проката и поковок из всех исследованных сплавов возрастает от $0,5 \ldots 2,2 \%$ до $3,0 \ldots 6,6 \%$ по сравнению с литым состоянием.

В связи с устранением микропористости, а также уменьшением общего газосодержания в деформированном металле удельный вес деформированных заэвтектических силуминов немного увеличивается. Так, удельный вес сплава $\mathrm{Al}-15 \% \mathrm{Si}$ возрастает от 2622,4 до 2634,0 кг $/ \mathrm{M}^{3}$, а удельный вес сплава $\mathrm{Al}$ - $20 \% \mathrm{Si}$ увеличивается от 2602,0 до 2614,5 кг/ $\mathrm{M}^{3}$.

Важной характеристикой алюминиевых сплавов является ТКЛР, отвечающий за стабильность размеров изделий космической техники [25]. В результате дилатометрического анализа установлено, что после проведения горячей пластической деформации ТКЛР возрастает в низкотемпературном интервале испытаний и значительно снижается при высоких температурах. Результаты измерений ТКЛР исследуемых сплавов представлены на рис. 3.

Так, средний ТКЛР литого сплава Al $15 \% \mathrm{Si}$ в интервале $50 \ldots 150{ }^{\circ} \mathrm{C}$ имеет значение $\bar{\alpha}_{50 \ldots 150}=18,1 \cdot 10^{-6}$ град $^{-1}$, тогда как деформированный сплав имеет значения $\bar{\alpha}_{50 \ldots 150}=20,2 \cdot 10^{-6}$ град $^{-1}$. Для сплава Al $20 \% \mathrm{Si}$ происходит незначительное увеличение ТКЛР в низкотемпературном интервале испытаний. Наибольшее увеличение значений ТКЛР наблюдается у сплава $\mathrm{Al}-30 \% \mathrm{Si}$. В этом случае после деформации средний ТКЛР равен $\bar{\alpha}_{50 \ldots 150}=18 \cdot 10^{-6}$ град $^{-1}$, тогда как значения литого сплава составляют $\bar{\alpha}_{50 \ldots 150}=15,8 \cdot 10^{-6}$ град $^{-1}$.

В высокотемпературном интервале испытания происходит значительное снижение ТКЛР всех исследуемых сплавов, подвергнутых деформации. Наибольшее снижение значений ТКЛР наблюдает-

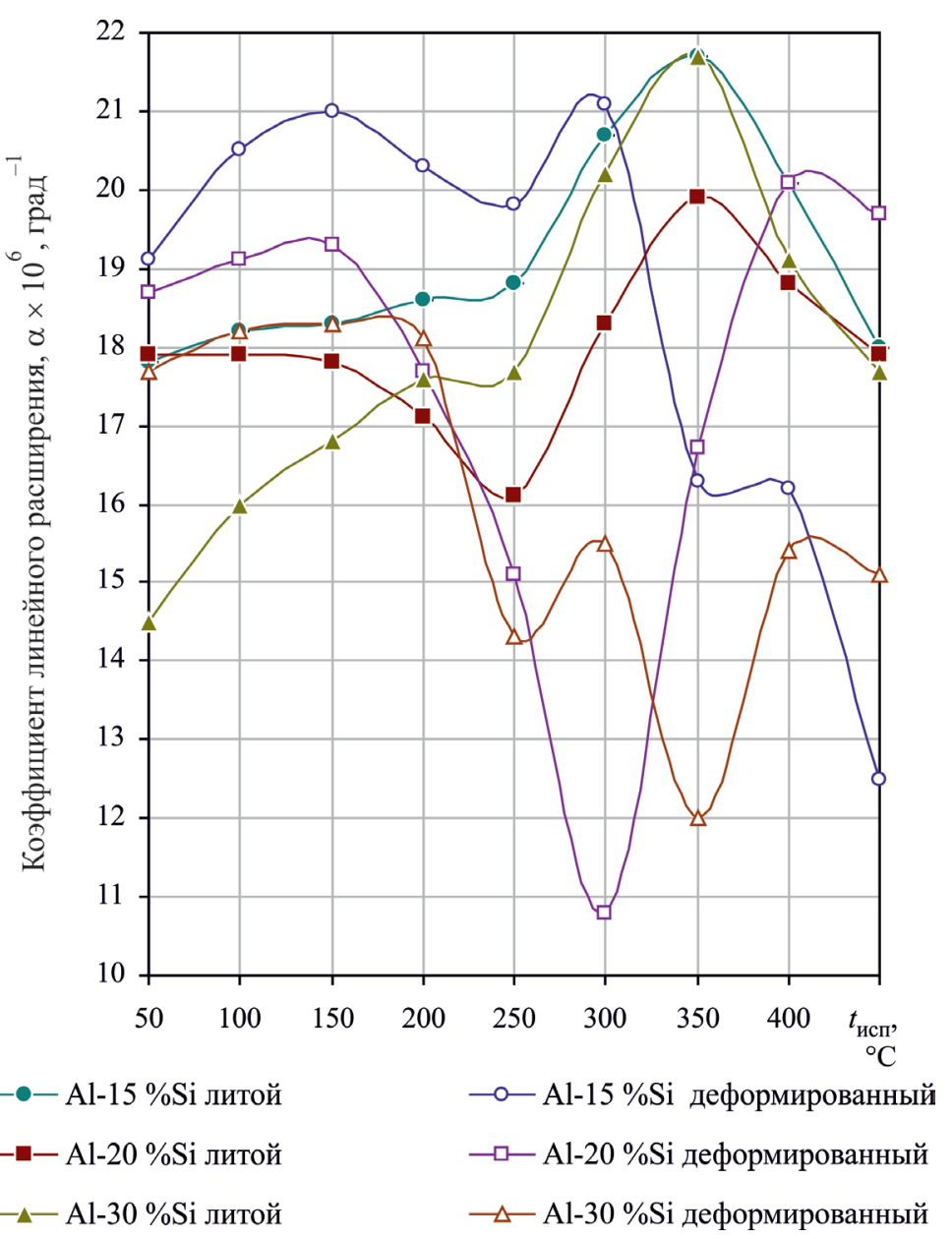

Рис. 3 Влияние деформации на ТКЛР модифицированных заэвтектических силуминов

Fig. 3. Influence of deformation on the TCLE of the modified hypereutectic silumin

ся у сплава $\mathrm{Al}$ - 30 \% Si. После деформации средний ТКЛР равен $\bar{\alpha}_{250 \ldots 450}=14,5 \cdot 10^{-6}$ град $^{-1}$, тогда как средние значения литого сплава составляют $\bar{\alpha}_{250 \ldots 450}=19,3 \cdot 10^{-6}$ град $^{-1}$.

Повышение ТКЛР в низкотемпературном интервале можно связать со значительным количеством дефектов кристаллического строения, а именно с увеличением плотности дислокаций и протяженностью межфазных границ, являющихся путями ускоренной диффузии для атомарного водорода. Вероятно, ускорение диффузионных процессов увеличивает тепловое расширение сплавов. Снижение значений ТКЛР при температурах выше $250 \ldots 300{ }^{\circ} \mathrm{C}$, видимо, связано с дегазацией полуфабрикатов и динамической рекристаллизацией структуры. Развитие этих процессов уменьшает количество диффузионноподвижного водорода и тем самым способствует снижению ТКЛР. 


\section{Выводы}

На основании проведенных исследований можно сделать следующие выводы.

1. Обработка расплава, увеличивающая содержание диффузионно-подвижного водорода в заэвтектических сплавах $\mathrm{Al}-\mathrm{Si}$, способствует диспергированию первичных и эвтектических кристаллов кремнистой фазы и даже получению в заэвтектическом сплаве эвтектической структуры, вследствие чего значительно повышаются механические свойства высококремнистых сплавов и их деформируемость.

2. Установлено, что горячая пластическая деформация модифицированных заэвтектических сплавов Al-Si способствует улучшению параметров их структуры, прежде всего измельчению и сфероидизации КПК и эвтектических частиц кремнистой фазы. При этом значительно повышаются их механические свойства: предел прочности возрастает в $1,5 \ldots 1,8$ раза, а относительное удлинение увеличивается в $2 . .4$ раза по сравнению с литым состоянием.

3. Дилатометрический анализ показывает, что проведение горячей пластической деформации модифицированных сплавов $\mathrm{Al}-15 \ldots 30 \% \mathrm{Si}$ способствует увеличению ТКЛР в низкотемпературном интервале испытаний и значительному его снижению при высоких температурах испытания.

\section{Список литературы}

1. Polmear I.J. Light alloys: from traditional alloys to nanocrystals. - Amsterdam: Elsevier Ltd, 2005.

2. Колачев Б.А. Водород в металлах и сплавах // Металловедение и термическая обработка металлов. - 1999. - № 3. - С. 3-11.

3. Hess P.D., Tumbull G.K. Effects of hydrogen on properties of aluminum alloys // Hydrogen in Metals / American Society for Metals. - Metals Park, Ohio: ASM, 1974. - P. 277-287.

4. Talbot D.E.J. Effects of hydrogen in aluminum, magnesium, copper, and their alloys // International Metallurgical Reviews. - 1975. - Vol. 20. - P. 166-184.

5. Борисов Г.П. О роли водорода в формировании структуры и свойств алюминиевых сплавов // Металлургия машиностроения. - 2005. - № 5. - С. 11-20.

6. Goltsov V.A. Fundamentals of hydrogen treatment of materials // Progress in Hydrogen Treatment of Materials. - Donetsk; Coral Gables: Kassiopeya Ltd, 2001. P. $161-184$.
7. Чернега Д.Ф., Бялик О.М. Водород в литейных алюминиевых сплавах. - Киев: Техника, 1972. C. $32-139$.

8. Уткин Н.И. Производство цветных металлов. 2-е изд. - М.: Интермет Инжиниринг, 2004. - 442 с.

9. Альтман М.Б., Лебедев А.А., Чухров М.В. Плавка и литье легких сплавов. - М.: Металлургия, 1969. $-680 \mathrm{c}$.

10. Чернега Д.Ф., Бялик О.М. Изменение содержания водорода и механических свойств сплава АЛ2 при многократной обработке его гексахлорэтаном // Технология и организация производства. - М.,1969. № 6. - C. 62-63.

11. Мороз Л.С, Чечулин Б.Б. Водородная хрупкость металлов. - М.: Металлургия, 1967. - 255 с.

12. Патент 3429695 США. Высокопрочный алюминиевый сплав и способ его обработки / Nakamura Hajime, Hori Toshimitsu, Sezaki Kazio. - Опубл. 25.02.1969.

13. Водород - легирующий элемент алюминиевых сплавов / В.К. Афанасьев, М.В. Попова, А.Н. Прудников, М.В. Зезиков, А.В. Горшенин // Известия вузов. Черная металлургия. - 2005. - № 6. C. $36-39$.

14. Density and thermal expansion of liquid AlSi alloys / J. Schmitz, B. Hallstedt, J. Brillo, I. Egry, M. Schick // Journal of Materials Science. -2012. Vol. 47, iss. 8. - P. 3706-3712.

15. Microstructure and mechanical properties of an Al-Si alloy consolidated by spark plasma sintering / T. Schubert, J. Schmidt, T. Weißgärber, B. Kieback// World Powder Metallurgy Congress \& Exhibition, PM 2010, Florence, Italy, October $10^{\text {th }}-14^{\text {th }} 2010$ : proceedings. - Shrewsbury: EPMA, 2010. - Vol. 2. P. 117-124.

16. Srivastava V.C., Mandal R.K., Ojha S.N. Microstructure and mechanical properties of Al-Si alloys produced by spray forming process // Materials Science and Engineering: A. - 2001. - Vol. 304-306. P. 555-558.

17. Structural and mechanical properties of Al-Si alloys obtained by fast cooling of a levitated melt / S.P. Nikanorov, M.P. Volkov, V.N. Gurin, Yu.A. Burenkov, L.I. Derkachenko, B.K. Kardashev, L.L. Regel, W.R. Wilcox // Materials Science and Engineering: A. - 2005. - Vol. 390, iss. 1-2. - P. 63-69.

18. Synthesis and formation process of $\mathrm{Al} 2 \mathrm{CuHx}$ : a new class of interstitial aluminum-based alloy hydride / H. Saitoh, S. Takagi, N. Endo, A. Machida, K. Aoki, S. Orimo, Y. Katayama // APL Materials. - 2013. Vol. 1, iss. 3. - doi: 10.1063/1.4821632.

19. Influence of additives on the microstructure and tensile properties of near-eutectic $\mathrm{Al}-10.8 \% \mathrm{Si}$ cast alloy / A.M.A. Mohamed, A.M. Samuel, F.H. Samuel, 
H.W. Doty // Materials and Design. - 2009. - Vol. 30, iss. 10. - P. 3943-3957.

20. Tensile and compressive deformation behavior of the $\mathrm{Al}-\mathrm{Si}-\mathrm{Cu}-\mathrm{Mg}$ cast alloy with additions of Zr, V and Ti / S.K. Shaha, F. Czerwinski, W. Kasprzak, D.L. Chen // Materials and Design. - 2014. - Vol. 59. P. $352-358$.

21. Monotonic and cyclic deformation behavior of the $\mathrm{Al}-\mathrm{Si}-\mathrm{Cu}-\mathrm{Mg}$ cast alloy with micro-additions of Ti, V and Zr / S.K. Shaha, F. Czerwinski, W. Kasprzak, J. Friedman, D.L. Chen // International Journal of Fatigue. - 2015. - Vol. 70. - P. 383-394.

22. Влияние обработки расплава водородосодержащими веществами на тепловое расширение алюминия / В.К. Афанасьев, М.В. Попова, М.А. Старо- стина (М.А. Малюх), Н.В. Кривичева // Металлургия машиностроения. - 2011. - № 3. - С. 30-33.

23. О влиянии водяного пара на формирование свойств высококремнистых Al-сплавов / В.К. Афанасьев, В.В. Герцен, С.В. Долгова, Ю.М. Мусохранов, М.В. Попова // Металлургия машиностроения. 2015. - № 5. - C. 17-21.

24. Спеченные материалы из алюминиевых порошков / В.Г. Гопиенко, М.Е. Смагоринский, А.А. Григорьев, А.Д. Беллавин; под ред. М.Е. Смагоринского. - М.: Металлургия, 1993. - 320 с.

25. Афанасьев В.К., Попова М.В., Самонь В.А. О создании новых легких деформированных сплавов для космической техники // Металлургия машиностроения. - 2014. - № 5. - С. 21-28.

\section{Конфликт интересов}

Авторы заявляют об отсутствии конфликта интересов.

(C) 2018 Авторы. Издательство Новосибирского государственного технического университета. Эта статья доступна по лицензии Creative Commons «Attribution» («Атрибуция») 4.0 Всемирная (https://creativecommons.org/licenses/by/4.0/) 


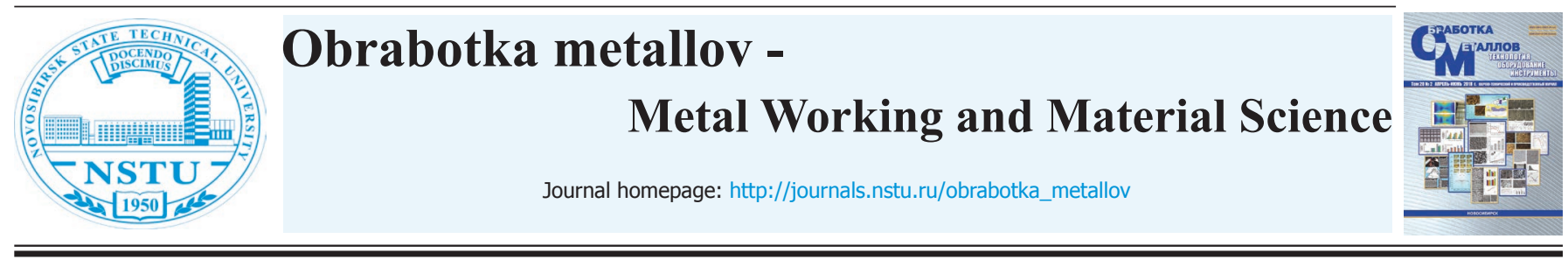

\title{
On the Participation of Hydrogen in the Formation of the Properties of Hypereutectic Al-Si Alloys
}

\author{
Vladimir Afanas'ev ${ }^{a}$, Marina Popova ${ }^{b,}$, ,Marina Malyuh ${ }^{c}$, Svetlana Dolgova ${ }^{d}$
}

Siberian State Industrial University, 42 Kirov str., Novokuznetsk, 654007, Russian Federation

${ }^{a}$ (D) https://orcid.org/0000-0003-0178-5471, @ in_afanaseva@mail.ru, ${ }^{b}$ (D) https://orcid.org/0000-0001-8010-9134, @ m.popova@rdtc.ru, ${ }^{c}$ (D) https://orcid.org/0000-0003-2299-9292, @ starostina_ma1976@mail.ru, ${ }^{d}$ (D) https://orcid.org/0000-0002-8044-196X, @ sv_dolgov@mail.ru

\section{ARTICLE INFO}

Article history:

Received: 02 February 2018

Revised: 26 February 2018

Accepted: 17 March 2018

Available online: 15 June 2018

Keywords:

Al-Si alloys

Hydrogen

The crystals of primary silicon Crystallization

Deformation

Temperature coefficient of linear expansion

\section{ABS TRACT}

Introduction. Aluminum alloys of special purpose are characterized by a certain combination of mechanical, physical, and physical-chemical properties due to operation under strictly defined conditions. In the development of new materials with improved technological properties, much attention is paid to alloys of the Al-Si system of hypereutectic concentration. It is known that the combined modifying agent comprising 2 or more elements outperform each component separately. A large number of ways to modify these alloys with the purpose of grinding the primary silicon crystals and eutectic is developed. Most known technologies are not widely applied in practice, therefore, the development of a method for modifying the melt of hydrogen-containing compounds remains a topical theme. Objective: development of technological method of processing the melt, providing for an increase of hydrogen content, for modifying the structure of the as-cast and obtaining the deformed $\mathrm{Al}-15 \ldots 30 \% \mathrm{Si}$ alloys with improved physical and mechanical properties. The parameters of the microstructure in the cast state and after the hot plastic deformation, as well as the mechanical characteristics of the modified alloys, are investigated. The study of the microstructure of the resulting alloys is undertaken. Research methods. Dilatometric tests, mechanical tests for static elongation, as well as metallographic analysis of the investigated alloys are used. The results and discussion. A new method of modification that allows reducing sharply the size of the primary crystals of the siliceous phase, resulting in greatly increased mechanical properties of high-silicon alloys and its deformability is suggested. Application of the developed method allows obtaining the structure of the eutectic type in hypereutectic Al-Si alloys. By obtaining the modified structure, characterized by an increased degree of dispersion of the constituents, a sharp decrease in the dimensions of the primary crystals of the brittle siliceous phase and a favorable change in its shape, plastic deformation of the investigated alloys became possible. It is found that hot deformation has a positive effect on the mechanical properties of Al-Si alloys, especially on its plasticity. It is shown that the complex of physicalchemical properties of deformed semi-finished products exceeds even the properties of sintered aluminum alloys.

For citation: Afanas'ev V.K., Popova M.V., Malyuh M.A., Dolgova S.V. On the participation of hydrogen in the formation of the properties of hypereutectic Al-Si alloys. Obrabotka metallov (tekhnologiya, oborudovanie, instrumenty) = Metal Working and Material Science, 2018, vol. 20, no. 2, pp. 63-74. doi: 10.17212/1994-6309-2018-20.2-63-74. (In Russian).

\section{References}

1. Polmear I.J. Light alloys: from traditional alloys to nanocrystals. Amsterdam, Elsevier Ltd, 2005.

2. Kolachev B.A. Vodorod v metallakh i splavakh [Hydrogen in metals and alloys]. Metallovedenie itermicheskaya obrabotka metallov = Metal Science and Heat Treatment, 1999, no. 3, pp. 3-11. (In Russian).

3. Hess P.D., Tumbull G.K. Effects of hydrogen on properties of aluminum alloys. Hydrogen in Metals. American Society for Metals. Metals Park, Ohio, ASM, 1974, pp. 277-287.

4. Talbot D.E.J. Effects of hydrogen in aluminum, magnesium, copper, and their alloys. International Metallurgical Reviews, 1975, vol. 20, pp. 166-184.

\footnotetext{
* Corresponding author

Popova Marina V., D.Sc. (Engineering), Associate Professor

Siberian State Industrial University,

42 Kirov str., Novokuznetsk,

654007, Russian Federation

Тел.: 8 (384) 346-32-91, e-mail: m.popova@rdtc.ru
} 
5. Borisov G.P. O roli vodoroda v formirovanii struktury i svoistv alyuminievykh splavov [On the role of hydrogen in formation of structure and properties of aluminum alloys]. Metallurgiya mashinostroeniya = Metallurgy of Machinery Building, 2005, no. 5, pp. 11-20. (In Russian).

6. Goltsov V.A. Fundamentals of hydrogen treatment of materials. In book. Progress in Hydrogen Treatment of Materials. Donetsk, Coral Gables, Kassiopeya Ltd, 2001, pp. 161-184.

7. Chernega D.F., Byalik O.M. Vodorod v liteinykh alyuminievykh splavakh [Hydrogen in cast aluminum alloys]. Kiev, Tekhnika Publ., 1972, pp. 32-139.

8. Utkin N.I. Proizvodstvo tsvetnykh metallov [Non-ferrous metals]. $2^{\text {nd }}$ ed. Moscow, Intermet Inzhiniring Publ., 2004. $442 \mathrm{p}$.

9. Al'tman M.B., Lebedev A.A., Chukhrov M.V. Plavka i lit'e legkikh splavov [Melting and casting of light alloys]. Moscow, Metallurgiya Publ., 1969. 680 p.

10. Chernega D.F., Byalik O.M. Izmenenie soderzhaniya vodoroda i mekhanicheskikh svoistv splava AL2 pri mnogokratnoi obrabotke ego geksakhloretanom [The change of hydrogen content and mechanical properties of the alloy AL2 in case of repeated processing of the hexachloroethane]. Tekhnologiya i organizatsiya proizvodstva [Technology and organisation of production]. Moscow, 1969, no. 6, pp. 62-63.

11. Moroz L.S, Chechulin B.B. Vodorodnaya khrupkost'metallov [Hydrogen embrittlement of metals]. Moscow, Metallurgiya Publ., 1967. 255 p.

12. Nakamura Hajime, Hori Toshimitsu, Sezaki Kazio. Vysokoprochnyi alyuminievyi splavi sposob ego obrabotki [High strength aluminum alloy and its production method]. Patent USA, no. 3429695, 1969.

13. Afanas'ev V.K., Popova M.V., Prudnikov A.N., Zezikov M.V., Gorshenin A.V. Vodorod - legiruyushchii element alyuminievykh splavov [Hydrogen - alloying element in aluminum alloys]. Izvestiya vysshikh uchebnykh zavedenii. Chernaya metallurgiya = Izvestiya. Ferrous Metallurgy, 2005, no. 6, pp. 36-39. (In Russian).

14. Schmitz J., Hallstedt B., Brillo J., Egry I., Schick M. Density and thermal expansion of liquid Al-Si alloys. Journal of Materials Science, 2012, vol. 47, iss. 8, pp. 3706-3712.

15. Schubert T., Schmidt J., Weißgärber T., Kieback B. Microstructure and mechanical properties of an Al-Si alloy consolidated by spark plasma sintering. World Powder Metallurgy Congress \& Exhibition, PM 2010, Florence, Italy, October $10^{\text {th }}-14^{\text {th }} 2010$, vol. 2, pp. 117-124.

16. Srivastava V.C., Mandal R.K., Ojha S.N. Microstructure and mechanical properties of Al-Si alloys produced by spray forming process. Materials Science and Engineering: A, 2001, vol. 304-306, pp. 555-558.

17. Nikanorov S.P., Volkov M.P., Gurin V.N., Burenkov Yu.A., Derkachenko L.I., Kardashev B.K., Regel L.L., Wilcox W.R. Structural and mechanical properties of Al-Si alloys obtained by fast cooling of a levitated melt. Materials Science and Engineering: A, 2005, vol. 390, iss. 1-2, pp. 63-69.

18. Saitoh H., Takagi S., Endo N., Machida A., Aoki K., Orimo S., Katayama Y. Synthesis and formation process of A12CuHx: a new class of interstitial aluminum-based alloy hydride. APL Materials, 2013, vol. 1, iss. 3. doi: $10.1063 / 1.4821632$.

19. Mohamed A.M.A., Samuel A.M., Samuel F.H., Doty H.W. Influence of additives on the microstructure and tensile properties of near-eutectic Al-10.8\%Si cast alloy. Materials \& Design, 2009, vol. 30, iss. 10, pp. 3943-3957.

20. Shaha S.K., Czerwinski F., Kasprzak W., Chen D.L. Tensile and compressive deformation behavior of the Al-Si-Cu-Mg cast alloy with additions of Zr, V and Ti. Materials \& Design, 2014, vol. 59, pp. 352-358.

21. Shaha S.K., Czerwinski F., Kasprzak W., Friedman J., Chen D.L. Monotonic and cyclic deformation behavior of the $\mathrm{Al}-\mathrm{Si}-\mathrm{Cu}-\mathrm{Mg}$ cast alloy with micro-additions of Ti, V and Zr. International Journal of Fatigue, 2015, vol. 70, pp. 383-394.

22. Afanas'ev V.K., Popova M.V., Starostina M.A. (Malyukh M.A.), Krivicheva N.V. Vliyanie obrabotki rasplava vodorodosoderzhashchimi veshchestvami na teplovoe rasshirenie alyuminiya [The influence of melt processing of hydrogenous substances on the thermal expansion of aluminium]. Metallurgiya mashinostroeniya $=$ Metallurgy of Machinery Building, 2011, no. 3, pp. 30-33. (In Russian).

23. Afanas'ev V.K., Gertsen V.V., Dolgova S.V., Musokhranov Yu.M., Popova M.V. O vliyanii vodyanogo para na formirovanie svoistv vysokokremnistykh Al-splavov [On the influence of water vapor on the formation of properties of high-silicon Al alloys]. Metallurgiya mashinostroeniya = Metallurgy of Machinery Building, 2015, no. 5, pp. 1721. (In Russian).

24. Gopienko V.G., Smagorinskii M.E., Grigor'ev A.A., Bellavin A.D. Spechennye materialy iz alyuminievykh poroshkov [Sintered materials of aluminum powders]. Moscow, Metallurgiya Publ., 1993. 320 p. 
25. Afanas'ev V.K., Popova M.V., Samon' V.A. O sozdanii novykh legkikh deformirovannykh splavov dlya kosmicheskoi tekhniki [The creation of a new strain of light alloys for space applications]. Metallurgiya mashinostroeniya $=$ Metallurgy of Machinery Building, 2014, no. 5, pp. 21-28. (In Russian).

\section{Conflicts of Interest}

The authors declare no conflict of interest.

(C) 2018 The Authors. Published by Novosibirsk State Technical University. This is an open access article under the CC BY license (http://creativecommons.org/licenses/by/4.0/). 